Theorizing the Production and Consumption of Live Music

A critical review

Arno van der Hoeven, Erik Hitters, Pauwke Berkers, Martijn Mulder and Rick Everts

This is a pre-print version of a chapter published in the book 'The Future of Live Music' (edited by Ewa Mazierska, Les Gillon, and Tony Rigg). This research was conducted in the context of the POPLIVE project (Staging Popular Music: Researching Sustainable Live Music Ecologies for Artists, Music Venues and Cities - www.poplive.nI).

Van der Hoeven, A., Hitters, E., Berkers, P., Mulder, M., \& Everts, R. (2020). Theorizing the Production and Consumption of Live Music: A critical review. In E. Mazierska, L. Gillon and T. Rigg, (eds.), The future of live music (pp. 19-33). New York: Bloomsbury Academic.

\title{
Introduction
}

Over the past decades, different theoretical perspectives have been developed that help to understand the social context in which live music is produced and consumed. Theories from the fields of sociology, cultural studies and popular music studies have enhanced our knowledge of (live) music industries and their impact on society. They help us to answer the central question that this book poses: How can we understand the future of live music? Theories offer models for understanding; they explain social phenomena, and structure data collection and analyses. In other words, theories allow us to make sense of social reality and can help us to think about future developments.

In this chapter, we will discuss different theoretical perspectives that have been used to study the production and consumption of live music. Each theory draws on a set of key 
assumptions, highlighting certain aspects of the live music industry over others. While this focus grants these theories their usefulness, it is insightful to compare these different approaches to get a better understanding of their contributions and shortcomings when it comes to the study of live music. We make this comparison at a time that the live music industry has undergone major transformations. On the production side, musicians increasingly depend on live concerts to earn a living in an already precarious labour market (Wikström 2009). New digital technologies have drastically altered the live music economy (Holt 2010). Furthermore, the live music infrastructure is changing through processes of festivalization and gentrification (Ballico and Carter 2018). These developments are related to changes on the consumption side of live music. Audience tastes are shifting, as omnivorous consumers have a wide range of competing cultural products to choose from in a globalized society (Berkers 2010; Chan 2019). Meanwhile, consumers’ willingness to pay for recorded music and see emerging talent has decreased (Naveed, Watanabe and Neittaanmäki 2017).

This chapter is structured as follows. The next sections, respectively, discuss sociological approaches to live music (art worlds and fields of cultural production), cultural studies approaches (subcultures, scenes and neo-tribes), network approaches (social network analysis and actor-network theory) and ecological approaches. Finally, we compare these different approaches and discuss what this comparison implies for the study of live music's future.

\section{Sociological approaches}

\section{Art worlds}

Together with field theory, the art worlds approach has been one of main ways to study the production of arts and culture with cultural sociology. Embedded in the tradition of Chicago 
sociology, this approach focuses on arts and culture as a consequence of occupational contingencies and problems rather than considering the supposed qualities of the works themselves (Martin 2006: 98). In his seminal book Art Worlds, Howard Becker (1982) defines such worlds in relation to three core elements. First, taking issue of the myth of the individual artistic genius, he argues that 'works of art [...] are not the products of individual makers, "artists" who possess a rare and special gift. They are, rather, joint products of all the people who cooperate [...] to bring works like that into existence' (1982: 35). Art is thus viewed as a collective activity instead of an individual product. Second, art worlds are characterized by a division of labour. Whereas core personnel are those actors who receive most recognition for doing 'artistic' work, support personnel - doing the 'hand work' - are equally essential in the production of any work of art. Hence, Becker (1982) invites us to 'think of all the activities that must be carried out for any work of art to appear as it finally does' (5). Third, conventions 'make collective activity simpler and less costly in time, energy, and other resources; but they do not make unconventional work impossible, only more costly and difficult’ (1982: 35). Conventions offer solutions for practical problems in the production of art, such as what materials will we use, how to convey meaning or emotion and who will do what? Art worlds have certain accepted conventions and do not reinvent the wheel each time. The 'art work' is the outcome of these choices.

Until recently, surprisingly few studies had adopted Becker's art world approach to study popular music (Martin 2006). Most of these works focus on music-making as a social process of people working together - in learning music, writing songs, coordinating tasks (Finnegan 2007; Lewis 1988). Yet, they often contextually address live music as well. For example, Lewis (1988) writes 'A live musical performance - to take just one example - is not solely the creation of the 
artist who happens to be performing. It is created by many cooperating individuals, established in a network within a specific art world, of whom the performer is one, albeit fairly important, element' (36). More recently, these ideas have been further developed into a music worlds approach, that is, collectives involved in making music (Bottero and Crossley 2011; Crossley and Bottero 2015). Whereas Becker's focus is more on the production of culture, making music here includes 'perceiving, interpreting, and appreciating, such that audiences belong to this collective, alongside artists and various support personnel' (Emms and Crossley 2018: 112). The audience is a particularly crucial aspect in the study of live music as the bodily presence in a physical space is what draws people to music (Berkers and Michael 2017). Moreover, the locus of a music world can be a musical style (e.g. punk), an ethos (e.g. DIY), an ideology (e.g. feminism), a locality (e.g. the Rotterdam music world) or a combination of elements (Emms and Crossley 2018: 114). Locality and its material implications are a particularly relevant specification of Becker's conceptualization for the study of live music as the local - often in relation to authenticity - has become increasingly important as a result of globalization (Bennett 1999a).

The art worlds approach has been critiqued on several grounds, also affecting its usefulness for studying live music. First and foremost, this approach has been extensively criticized for its lack of attention to conflict. In line with symbolic interactionism, Becker's work strongly focuses on doing things together, seemingly ignoring power structures and power struggles (Bottero and Crossley 2011). Yet, issues of inequality are at the heart of live music. Not only are few musicians able to make a living from live music, but success is also unequally distributed by, for example, gender (e.g. Savigny and Sleight 2015). In order to address the latter issue, the Keychange project has successfully encouraged 100+ festivals to pledge to achieve a 
50:50 gender balance by 2022. Second, Becker's art world approach focuses specifically on how conventions help to coordinate collective action; yet, pleasure and commitment of participants also play a crucial role in doing things together (Crossley and Bottero 2015), which have largely remained unaddressed.

\section{Fields of cultural production}

A second more widely used approach to study music has been field theory, even though Bourdieu himself 'rarely engaged with music directly or in any detail' (Prior 2011: 126). According to Bourdieu, a field can be defined as 'a field of forces within which the agents occupy positions that statistically determine the positions they take with respect to the field, these position-takings being aimed at either conserving or transforming the structure of relations of forces that is constitutive of the field' (Bourdieu 2005: 30). In the field of live music, agents include booking agencies, artists, concert organizers and promotors who struggle over what a 'good' live concert is and who determines how it should sound and look like. Fields operate at three levels: macro-, meso- and micro-level.

At the macro-level, fields operate relatively independently of each other. This means each field is rather autonomous (Bourdieu 1993), that is, it has its own logic (autonomous pole) but is also influenced by other logics (heteronomous pole). In fields of artistic production, the autonomous logic is that of cultural capital, where a good artist is defined as an aesthetically innovative artist, agents have faith in critics and gallerists as ‘brave discoverers' of such artists and the focus is on long-term rewards (positive reviews, canonization). At the other end of the field, the heteronomous pole is dominated by the logic of economic capital, where a good artist is a successful artist and agents rely on audience demand and short-term rewards from the market, 
represented by sales figures. The degree of autonomy can be measured by strength of negative sanctions on violation of the field logic. Within the study of popular music, much research has used Bourdieu's conceptualization of relative autonomy to address the distinction between mainstream pop music - the commercial, heteronomous pole of the pop music field - and alternative music - the more autonomous restricted field of pop music production (Hesmondhalgh 2006; Negus 1995).

At the meso-level, the functioning of the field is affected by doxa, the common - often undisputed - rules of the game. For example, agents within the field of artistic production often share the idea that it is possible to objectively distinguish 'good' art from 'bad' art. Yet, they battle over what is good and bad art (legitimacy) and who should define it (power of consecration). This struggle often occurs between those dominating the field (orthodoxy) and those trying to change the field (heresy). For example, Prior (2008) discusses how the new genre of glitch 'remains a sonic signifier of experimentation, and its defence is felt by protagonists to be a matter of cultural purity’ (310). Guerra shows (2016: 624) how alternative rock bands entered the Portuguese field of music production by, for example, following a logic of sonic exploration and experimentation and avoiding involvement with major labels.

At the micro-level, a field is a network of objective relations between positions and homologous position-takings. Agents occupy different objective positions, affecting the behaviour of, for example, artists or bookers in artistic field. However, they take these positions differently, depending on - among other things - the characteristics of those who occupy that position. For example, bookers support different artists and different styles to position themselves in a particular way in artistic fields. 
The field of cultural production approach has been critiqued on several grounds, also affecting its usefulness for studying live music. First, as Hesmondhalgh (2006) has pointed out, 'It is simply astonishing how little Bourdieu has to say about large-scale, "heteronomous" commercial cultural production’ (217). Yet, this pole is highly important in popular music. Second, a major drawback for our study is that it lacks a spatial component. Bourdieu does address the social space, but it links more to relationships than material location. Although this perspective is helpful to understand how power affects the field of live music at different levels, it fails to address how it is locationally and commercially embedded.

\section{Cultural studies approaches}

\section{Subcultures}

There are two sociological traditions that have developed subcultural thinking, mainly in relation to youth cultures. An early conceptualization of subculture was developed by Chicago School sociologists in the 1920s. Their subcultural research was aimed at understanding deviant youth behaviour in situations of urban fragmentation and marginalization and as such they did not develop a subcultural theory. Subculture for them was primarily a social subsystem which emerged among urban poor, youth and criminal groups in reaction to dominant cultural and economic forces (Williams 2007). Subcultural theory was further developed in the 1970s by the Centre for Contemporary Cultural Studies (CCCS) at the University of Birmingham in order to understand the intersections between youth culture, music, style and taste. A subculture in general terms 'is a group with certain cultural features that enable it to be distinguished from other groups and the wider society from which it has emerged' (Muggleton 2007). For the CCCS theorists, subcultures are inherently class-based, acting out resistance to dominant cultures in 
style, musical taste and deviant behaviour. In this, it adds to the American tradition as it is not just understood as deviance, but puts a focus on the symbolic (stylistic) solutions of workingclass youth for class struggles. Nevertheless, it does recognize that the protagonists' intentions were not always to resist, nor that actual change to class relations was achieved (Hebdige 1979; Muggleton and Weinzierl 2003; Williams 2011).

Subcultural research has contributed considerably to the understanding of the importance of music to youth cultures, but it has also sparked a debate on whether the concept is still useful in the digital age. According to Andy Bennett, the usage of 'subculture' may be 'deeply problematic in that it imposes rigid lines of division over forms of sociation which may, in effect, be rather more fleeting, and in many cases arbitrary, than the concept of subculture, with its connotations of coherency and solidarity, allows for' (Bennett 1999b: 603). This can also be related to the particular historical circumstances, as pointed out by Hesmondhalgh (2005: 38), in which the study of popular music intersected with youth studies, which tended to privilege youth in the study of music and society. In addition, post-subculturists criticized subcultural thinking by contending that subcultures have become commodified and commercialized. They consist of many small, diverse and fluid groups in an age where there is no hegemonic mainstream to resist and the line between subcultures and mainstream becomes increasingly diffuse (Williams 2011: 34). This commodification and commercialization of youth culture has accelerated with the increasing centrality of technology and digital media in everyday life. Bennett (2014) points to the relevance of post-subcultural perspectives to understand how the advent of new media brings changing forms of social-cultural affiliation and identity. Meanwhile, others defend the use of the term 'subculture', arguing that this debate has become polarized through too narrow 
interpretations of the concept (Hodkinson 2016). The subcultures/post-subcultures debate is not likely to become less heated in the years to come.

\section{Scenes and neo-tribes}

While subcultures have been widely used to look at in- versus out-group dynamics in genre- and style-based communities, the scene approach has been arguably the most influential one in popular music studies, and one that has been developed from music research to begin with. Based in cultural studies, scene approaches take account of historical change within national and international music cultures and offer useful insights into the role of space and place in musical production and consumption. Scenes can be understood as loosely bounded networks of actors (e.g. performers, journalists and fans) who collectively contribute to what they perceive as a specific genre of music (Straw 1991; Shank 2011; Bennett and Peterson 2004; Berkers and Schaap 2018). This concept was later developed to include other forms of cultural expressions as well, while a valuable addition to the subcultural perspective is that it is also mindful of scenes' connections to global cultural flows and industries. In particular, Bennett's and Petersons's (by now) classic collection of Music Scenes (2004) has pointed at the mostly local, or at least geographically bounded origins of scenes, while at the same time underscoring their connection to trans-local or virtual communities and (industrial) networks.

However, while scene approaches principally map socially networked worlds of actors, institutions and intermediaries, a criticism is that it remains rather descriptive and vague and bears in it the risk of being conflated to describing musical (and music-associated) practices occurring within a particular geographical space (Hesmondhalgh 2005). In many cases it has merely been used to describe actors within their localized music communities (one genre, one 
city). The concept is thus rendered merely descriptive instead of analytical of even theoretical. Widening up the scene perspective in order to move beyond the local, and using it holistically to encompass 'the sum total of all global phenomena surrounding a subgenre' (Straw 2001: 248) contributes even more to the muddling of the concept and its problematic elasticity (Hesmondhalgh 2005: 29).

Andy Bennett’s (Bennett 1999b) neo-tribalism is another critique of subcultural theory. It is based on Maffesoli, and aims to overcome the contradictory usages of subcultures, as well as the overestimation of the coherence of youth groups. He adds a lifestyle and performative element to do justice to the 'unstable and shifting cultural affiliations which characterize late modern consumer-based identities' (605). The tribe, then, is a more fluid notion; a state of mind, expressed and performed through lifestyle. Especially the performative and lifestyle element opens up possible usages of the neo-tribe concept in the analysis of live music, particularly for research with a focus on audience behaviour and experiences. In the setting of electronic dance clubs and festivals, it may help to better understand the appeal of eclecticism in musical styles, value creation and lifestyle and 'tribal' rituals and staged behaviours.

\section{Network approaches}

\section{Social Network Analysis}

Although Social Network Analysis (SNA) is actually a method, it is relevant to discuss it here because various researchers have fruitfully applied it in relation to theorizations of music production. Furthermore, this method comes with a conceptual apparatus that enhances our understanding of spatial and historical dynamics in live music. In their edited volume on social networks in music, Crossley, McAndrews and Widdop (2014) position their book as a 
contribution to the research on 'music worlds'. Building on Howard Becker's understanding of collective action in art worlds, SNA can chart the networks of people (e.g. musicians or support personnel) and non-human things (e.g. venues and musical styles) that play a role in the production and consumption of music. In so doing, SNA enables an exploration of the connections and interactions within a particular 'music world'. Two basic elements in any network are nodes and ties (Crossley, McAndrews and Widdop 2014). Nodes concern the objects in a network, which are connected through ties. Additionally, a set of node attributes can be included in a study, which give additional information about the nodes such as the gender or income of, or the instrument played by, a musician.

Crossley and Emms (2016) have used SNA to study the relationships between different music worlds (e.g. metal, jazz and mainstream) in the universe of UK music festivals. They have aimed to move beyond the existing literature by not focusing on a particular music world in isolation, but at the connections within a common 'musical universe'. In their analysis, Crossley and Emms looked at the extent to which distinct 'worlds' can be identified within the wider festival universe. They did so by examining the artist rosters of 106 music festivals in the 201113 period, recording whether festivals shared the same artists. The authors found that although the different festivals were connected to each other, separate music worlds could be identified. In particular, jazz, metal and folk festivals form distinct worlds within the network of UK music festivals. Furthermore, the analysis shows that the mainstream is situated in the core of this 'festival universe'. This study illustrates how SNA can be useful to assess the cohesion within a network and the extent to which they are isolated from other music worlds.

Another interesting application of SNA to live music research is Emms and Crossley's (2018) study of the connections between events in the underground heavy metal music world. 
Using interviews and surveys, they analysed the events attended by audience members in six localities in the UK. In so doing, they observe how a translocal music world consists of geographically dispersed networks, in which there are some central localities of musical activity. This means that the flows of audience members between different localities result in translocal networks within the underground heavy metal music world. In particular, the authors found that festivals are central to the generation of translocality. Festivals attract bigger audiences and the survey respondents are more likely to travel to festivals in other cities than to concerts.

A relative disadvantage of SNA is that it lacks the rich qualitative depth provided by other approaches. As Crossley and Emms (2016: 2) argue about SNA:

Its own limitations, which stem largely from its exclusive focus upon ties and its insensitivity to their qualitative nuances and complexity, mean that it can never substitute for a rich, qualitative investigation of a music world. However, the centrality of networks to such worlds and SNA's aforementioned capacity to handle and analyse relational data make it a powerful addition to the cultural sociologist's toolbox.

Nevertheless, the integration of qualitative methods and archival research can help to understand the relationships between the nodes in the network (Crossley 2009). The research on underground metal by Emms and Crossley (2018) shows how interviews can be used to further understand and contextualize the findings from formal SNA.

To conclude, SNA can complement many of the other approaches to live music. Despite the methodological and theoretical differences, SNA shares a focus on relationality with ActorNetwork Theory, field theory and the music ecologies approach. However, Emms and Crosley (2018: 132) argue that SNA enables a more precise analysis of relationality and structure than other approaches in which networks 'remain a vague place-marker for who knows what'. 


\section{Actor-network theory}

Actor-network theory (ANT), which has its roots in science and technology studies, is concerned with the assemblages of human and non-human actors that enable a certain event, product or situation to happen in the social world. It allows researchers to open the 'black box' of cultural production, shedding light on how the relationships between actors generate particular outcomes. Gander (2011) clarifies the difference between SNA and ANT by stating that for the latter networks do not simply connect but actively construct links. In other words, the focus in ANT is on how things become rather than just the connections between them.

Gander's PhD thesis on the creation of pop songs is an example of how ANT can be used to uncover the process behind the production of cultural goods. Instead of seeing the creation of a musical product as the transmission of a recorded piece of music into the market, he looks at what happens in the pipeline. ANT allows Gander to trace how a pop song is produced in the moments of songwriting, recording, mixing, mastering and live performance. In this process, non-human actors such as sound, instruments and space play a vital role. During a live music performance, the song as recorded in the studio shapes the way in which it is performed on stage. At the same time, the live setting creates a new assemblage of human and material objects. Factors that affect the live performance are, for example, the audience, the size of the venue and the atmosphere.

Another application of ANT to live music performance is Chesher's (2007) study of mobile phone use at a U2 stadium concert. Among other things, he asks how 'thousands of individuated connections mediated by mobile phones transform a "mass” spectacle' (Chesher 2007: 217). In the ethnographic style characteristic of ANT, Chesher observes the different ways in which audiences use their mobile phones at the performance. For example, they use it to locate 
each other in the stadium, to record the show or just to kill time. The mobile phones even become part of the performance when U2 singer Bono asks the audience to 'set the stadium alight' with their mobile phones. After the song ends, Bono invites the audience to express their support for the 'make poverty history' campaign by sending a SMS. Chesher describes how during the concert some of the names of those in attendance scroll across the stadium screen. Furthermore, the next day a text message follows from Bono to raise awareness of the 'make poverty history' website. Again, the assemblage of various human and non-human actors enables this specific situation to happen. As Chesher reminds us, this includes offstage associations such as the touring crew and the innovations made possible by the mobile phones.

In these studies on live music, ANT is used to uncover the networks of human and nonhuman actors that enable live music events. Focusing on the role of festivals in contemporary cities, Nunes (2019: 5) explains the benefits of using ANT as follows:

We applied Latour's theory because it allows us to represent the views of diverse research subjects in a rich and multi-vocal way. From this perspective, the investigation process becomes more collaborative than other forms of qualitative work. Importantly, it allows us to capture the complexity of the research site through strategies such as multivocal writing, use of images and primary resources.

However, contrary to SNA, ANT does not offer a formal analysis of the relations within a network. Furthermore, applications of ANT often remain very descriptive, offering relatively little theoretical or methodological development.

\section{Ecological approaches to live music}


The concept of 'ecology' is increasingly used to describe the relationships between actors in specific sectors and their embeddedness in a wider environment. The term has been used both in policy and in academic fields to analyse, for example, media ecologies (Baltruschat 2010), the cultural ecology (Holden 2015), more specifically, news ecologies (Lowrey 2012) and live music ecologies (Behr et al. 2016; Elbourne 2013). The advantage of the term 'ecology' is that it has a broad scope and allows a holistic approach to the connections between diverse actors and the material conditions in a sector. Furthermore, it is associated with a range of other concepts such as 'resilience', 'sustainability’ and 'diversity', which enable an analysis of how ecologies deal with external threats and disruptions. However, the term 'ecologies' has also been understood as a buzzword that is conceptually vague (Behr et al. 2016) and as an inappropriate application of a naturalistic trope (Keogh 2013).

Particularly relevant to the study of music has been the ethnomusicological approach developed by Schippers and Grant (2016). Building on analogies with the natural world, they are mostly concerned with the sustainability of particular musical forms and communities across the globe. Their focus is mainly on performance-based traditional music practices, ranging from Ghanese Dance-Drumming to Balinese Gamelan performances. Musical practice, in their view, is embedded within a larger framework of an ecosystem consisting of musicians and their communities, traditions and institutions of learning and teaching; infrastructure and regulations; media, audiences and the music industry and contexts and constructs such as identities, values and aesthetics. For them, an ecological approach is primarily a tool to map, explore, understand and clarify what factors are conducive for particular music practices. A 'deep awareness of these main factors in musical ecosystems and their interrelationships can be a powerful tool to ensure the cultural diversity of our planet' (Schippers 2016: 17). This suggests that ecology approaches 
may promote issues of sustainability and diversity of particular traditional musical forms.

Another take on the ecological approach was developed by British music researchers (Behr et al. 2016) in the context of the Live Music Exchange project. This perspective focuses on the changing ways in which different actors contribute to the qualities of the live music sector. It views the live music ecology as a (inter)local network of different social actors within live music (e.g. musicians, concert organizers, agents) and beyond (e.g. regulators, policy makers, sponsors). The ecological perspective pays due attention to the material aspects of live music, such as the size of music venue and the urban setting in which music events take place. These material aspects affect, for example, acoustics and the kind of bands that can be booked. The intangible aspects of live music ecologies concern, among other things, the musical experience and the histories associated with a specific venue. Taken together, these material and intangible dimensions of live music can shed light on the ‘health’ of specific live music ecologies. 'Healthy' music ecologies include venues of varying sizes, which cater for different music audiences and bring diversity to the local music culture. However, while discussing ecologies in terms of 'healthy/unhealthy' (Webster and Behr 2013), their approach offers little clarity on what makes a live ecology ‘healthy’ (sustainable) or how we should measure this.

Although this research has firmly positioned the ecological approach in the study of live popular music, its focus was largely on the British context, on the genre of rock/pop music and on permanent venues. As a result of their local social and material embeddedness, live music ecologies are both deeply relational and highly contextual. Previous music industry studies (Rutten 1991) show how artists in smaller internal markets have more difficulty exploiting rights than their British counterparts. As a result, they rely more on live performances. Furthermore, following the increasing popularity and urbanization of festivals - and processes of 
festivalization, popular music festivals are taking central stage in the live music production system. In addition, cities have always been places of diversity and hubs of various mobilities, for example, touring music acts. Despite the global appeal and interconnectedness of music ecologies, local music cultures have remained important in creative industries and policies. An ecology approach allows for an integrated analysis of the local, national and internationally interwoven structures of the (live) music industries.

Some remarkable similarities between ANT and the live music ecology approach can be observed. Like ANT, the ecological approach to live music performance is concerned with the different relationships that enable the social events of concerts (Behr et al. 2016). Moreover, for both approaches these relationships include non-living actors such as the type of venue and transport links. The connections between the ecology metaphor and ANT are explicitly made by Piekut (2014: 212) in a study of music history writing:

An ecology is a web of relations, an amalgamation of organic and inorganic, or biological and technological, elements that are interconnecting and mutually affecting. In other words, like experimentalism or anything else, an ecology is an emergent, hybrid grouping that connects many different kinds of things. It has real boundaries that mark it off as distinct from its surrounding environment, but those boundaries are variable and open. Both perspectives thus allow researchers to understand the complex relationships between human and non-human elements that affect the production of live music performance.

While the ecology approach suggests the integration of the micro-, meso- and macrolevels of music ecologies, current applications hardly ever pay serious attention to it. Underscoring the macro-level complexity of music practices, the ways in which these affect meso-level institutions, micro-level interactions (e.g. impact of festivalization on audience 
experiences, or local effects of globalized music promotion) and consumption and performance practices tend to remain hidden. It offers the possibility to consider qualities of sustainability of the macro context of (live) music but should also take the temporally specific nature of performances into account. This perspective is useful to analyse the structure of social relations between different actors and how that contributes to the qualities of the live music sector and the sustainability of live music cultures, including the material aspects of live music (e.g. characteristics the of music venue) and intangible dimensions (e.g. the histories associated with a specific venue).

\section{Conclusions: Theorizing the future of live music}

This chapter has reviewed different theoretical perspectives on the social context in which live music is produced and consumed. As popular music has become a central element in people’s lives and interactions, the study of this cultural form has also been increasingly institutionalized through dedicated journals and academic conferences. In terms of its theoretical underpinnings, this academic field is as diverse as its study object. It includes social-scientific, interpretivist and critical approaches. As Hesmondhalgh (2005: 32) argues, we need an 'eclectic array of theoretical tools’ instead of an overarching master concept.

Over the years, the field of popular music has been enriched by fruitful crossovers between disciplines such as sociology, cultural studies and media studies. In fact, most concepts in popular music studies have been adapted from other disciplines. Meanwhile, social scientists use music as a case to advance their own theories. Due to its ubiquitous nature, music is a vital lens to study contemporary and future societal developments. For example, Krueger argues that 
'musicians have long been at the vanguard of the gig economy' (2019: 55), struggling with issues of precarious labour that many people face today in the digital gig economy.

The different theoretical perspectives discussed in this chapter all share a concern with the social relationships that both shape and are constituted by live music performances. Furthermore, scenes, fields, social networks, subcultures and ecologies all have, in one way or the other, local manifestations. These theories underscore that local music infrastructures of venues, festivals and organizations are essential for this cultural form, because the performance always takes places somewhere. Indeed, an important factor in live music's appeal is its immediacy and social experience. Nevertheless, live music theories are increasingly challenged to also conceptualize the global and mediated nature of the live music industry. New technologies affect how people engage with this cultural form before concerts (e.g. interactions on social network sites), during the performance (e.g. concerts using virtual reality) and after the event (e.g. sharing videos online).

In a globalizing and digitalizing society, it is not surprising that many publications cited in this chapter approach live music from a network perspective. The concept of networks is useful to understand how connections between actors in different geographical and virtual places shape processes of production and consumption of live music. As the digitalization of society is likely to continue in the years to come, network approaches to live music are a welcome tool to understand the dynamics in this sector. Another theoretical trend is to use a holistic perspective, which serves a similar purpose of understanding the connections between different institutions and people. Indeed, the ecological approach to live music demonstrates that each gig is enabled by a range of actors in and outside the field of music such as regulators, policy makers and transnational conglomerates (Behr et al. 2016). In order to understand the future of live music, 
theoretical attention to these power relations is vital to analyse how and what kind of concerts are organized.

It is hard to predict the future of live music theorization, but it is likely to stay eclectic since theoretical concepts rarely leave the stage. 'Subculture’s Not Dead!’ (Williams 2019), proclaims a recent article about this contested concept. Even if concepts are heavily criticized, they sometimes resurface or are still widely cited as a yardstick to compare new work. While the stage of popular music studies is thus filling up with a growing number of concepts, the show must go on. New technologies, changing forms of social interaction and economic developments require that music scholars improve and expand their theoretical repertoire. Future theories of live music's product and consumption must be verifiable, able to guide data collection and be specific enough to explain processes of live music production and consumption. In other words, these theories need to be attentive to the complexities of this cultural form without becoming fuzzy.

\section{Acknowledgements}

This work was supported as part of the project Staging Popular Music: Researching Sustainable Live Music Ecologies for Artists, Music Venues and Cities (POPLIVE) by the Netherlands Organisation for Scientific Research (NWO) and the Taskforce for Applied Research (NRPOSIA) [grant number 314-99-202, research programme Smart Culture - Arts and Culture]. Partners in this project are Mojo Concerts and the Association of Dutch Pop Music Venues and Festivals (VNPF). 


\section{References}

1. Ballico, Christina and Dave Carter (2018). 'A State of Constant Prodding: Live Music, Precarity and Regulation', Cultural Trends, 3: 203-17.

2. Baltruschat, Doris (2010). Global Media Ecologies: Networked Production in Film and Television, London: Routledge.

3. Becker, Howard (1982). Art Worlds, Berkeley: University of California Press.

4. Behr, Adam, Matt Brennan, Martin Cloonan, Simon Frith and Emma Webster (2016). 'Live Concert Performance: An Ecological Approach’, Rock Music Studies, 1: 5-23.

5. Bennett, Andy (1999a). 'Hip Hop Am Main: The Localization of Rap Music and Hip Hop Culture’, Media, Culture \& Society, 21: 77-91.

6. Bennett, Andy (1999b). 'Subcultures or Neo-Tribes? Rethinking the Relationship between Youth, Style and Musical Taste’, Sociology, 3: 599-617.

7. Bennett, Andy (2014). 'Youth Culture and the Internet: A Subcultural or Post-subcultural Phenomena?', in The Subcultures Network (eds.), Subcultures, Popular Music and Social Change, Newcastle Upon Tyne: Cambridge Scholars, pp. 89-104.

8. Bennett, Andy and Richard A. Peterson, eds (2004). Music Scenes: Local, Translocal and Virtual, Nashville: Vanderbilt University Press.

9. Berkers, Pauwke (2010). 'Gendered Scrobbling: Listening Behaviour of Young Adults on Last.fm’, Interactions: Studies in Communication \& Culture, 3: 279-96.

10. Berkers, Pauwke and Janna Michael (2017). ‘Just What Makes Today’s Music Festivals so Appealing?', in Peter Koudstaal (ed.), Music Brings us Together: Music \& Art Festivals, Den Haag: Uitgeverij Komma, pp. 98-115.

11. Berkers, Pauwke and Julian Schaap (2018). Gender Inequality in Metal Music Production, Bingley: Emerald Publishing.

12. Bottero, Wendy and Nick Crossley (2011). 'Worlds, Fields and Networks: Becker, Bourdieu and the Structures of Social Relations', Cultural Sociology, 1: 99-119.

13. Bourdieu, Pierre (1993). The Field of Cultural Production: Essays on Art and Literature, London: Polity.

14. Bourdieu, Pierre (2005). 'The Political Field, the Social Science Field, ant the Journalistic Field', in Rodney D. Benson and Erik Neveu (eds), Bourdieu and the Journalistic Field, Cambridge, Malden, MA: Polity, pp. 29-47. 
15. Chan, Tak Wing (2019). 'Understanding Cultural Omnivores: Social and Political Attitudes', The British Journal of Sociology, 3: 784-806.

16. Chesher, Chris (2007). 'Becoming the Milky Way: Mobile Phones and Actor Networks at a

U2 Concert', Continuum, 2: 217-25.

17. Crossley, Nick (2009). 'The Man Whose Web Expanded: Network Dynamics in

Manchester’s Post/Punk Music Scene 1976-1980', Poetics, 1: 24-49.

18. Crossley, Nick and Rachel Emms (2016). 'Mapping the Musical Universe: A Blockmodel of UK Music Festivals, 2011-2013’, Methodological Innovations, 9: 1-14.

19. Crossley, Nick and Wendy Bottero (2015). 'Music Worlds and Internal Goods: The Role of Convention', Cultural Sociology, 1: 38-55.

20. Crossley, Nick, Siobhanand McAndrew and Paul Widdop, eds (2014), Social Networks and Music Worlds, London: Routledge.

21. Elbourne, Martin (2013). Reverb: Adelaide's Live Music Movement, the Future of Live Music in South Australia, Adelaide: The Don Dunstan Foundation.

22. Emms, Rachel and Nick Crossley (2018). 'Translocality, Network Structure, and Music Worlds: Underground Metal in the United Kingdom', Canadian Review of Sociology/Revue Canadienne de Sociologie, 1: 111-35.

23. Finnegan, Ruth (2007). The Hidden Musicians: Music-making in an English Town, Middletown, CT: Wesleyan University Press.

24. Gander, Jonathan (2011). Performing Music Production: Creating Music Product, PhD Thesis, King's College London.

25. Guerra, Paula (2016). 'Keep It Rocking: The Social Space of Portuguese Alternative Rock (1980-2010)', Journal of Sociology, 4: 615-30.

26. Hebdidge, Dick (1979). Subculture: The Meaning of Style, London: Routledge.

27. Hesmondhalgh, David (2005). 'Subcultures, Scenes or Tribes? None of the Above', Journal of Youth Studies, 1: 21-40.

28. Hesmondhalgh, David (2006). 'Bourdieu, the Media and Cultural Production', Media, Culture \& Society, 2: 211-31.

29. Hodkinson, Paul (2016). 'Youth Cultures and the Rest of Life: Subcultures, Post-subcultures and Beyond', Journal of Youth Studies, 5: 629-45. 
30. Holden, John (2015). The Ecology of Culture, Swindon: Arts and Humanities Research Council.

31. Holt, Fabian (2010). 'The Economy of Live Music in the Digital Age', European Journal of Cultural Studies, 2: 243-61.

32. Keogh, Brent (2013). 'On the Limitations of Music Ecology', Journal of Music Research Online, 4: 1-10.

33. Krueger, Alan (2019). Rockonomics: A Backstage Tour of What the Music Industry Can Teach Us about Economics and Life, New York: Currency.

34. Lewis, George H. (1988). 'The Creation of Popular Music: A Comparison of the "Art Worlds” of American Country Music and British Punk', International Review of the Aesthetics and Sociology of Music, 1: 35-51.

35. Lowrey, Wilson (2012). 'Journalism Innovation and the Ecology of News Production: Institutional Tendencies', Journalism \& Communication Monographs, 14: 214-87.

36. Martin, Peter J. (2006). 'Musicians’ Worlds: Music-Making as a Collaborative Activity', Symbolic Interaction, 1: 95-107.

37. Muggleton, David (2007). 'Subulture', in George Ritzer (ed.), The Blackwell Encyclopedia of Sociology, New York, NY: Blackwell Publishing.

38. Muggleton, David and Rupert Weinzierl (2003). The Post-subcultures Reader, London: Berg.

39. Naveed, Kashif, Chihiro Watanabe and Pekka Neittaanmäki (2017). 'Co-evolution between Streaming and Live Music Leads a Way to the Sustainable Growth of Music Industry-Lessons from the US Experiences', Technology in Society, 50: 1-19.

40. Negus, Keith (1995). 'Where the Mystical Meets the Market: Creativity and Commerce in the Production of Popular Music', The Sociological Review, 2: 316-41.

41. Nunes, Paulo (2019). 'Cities Regulated by Cultural Events: Tracking Music Festivals in Lisbon and São Paulo', International Journal of the Sociology of Leisure, 1-2: 147-62.

42. Piekut, Benjamin (2014). 'Actor-Networks in Music History: Clarifications and Critiques', Twentieth-Century Music, 2: 191-215.

43. Prior, Nick (2008). 'Putting a Glitch in the Field: Bourdieu, Actor Network Theory and Contemporary Music', Cultural Sociology, 3: 301-19. 
44. Prior, Nick (2011). 'Critique and Renewal in the Sociology of Music: Bourdieu and Beyond', Cultural Sociology, 1: 121-38.

45. Rutten, Paul (1991). 'Local Popular Music on the National and International Markets', Cultural Studies, 3: 294-305.

46. Savigny, Heather and S. Sam Sleight (2015). 'Postfeminism and Heavy Metal in the United Kingdom: Sexy or Sexist?', Metal Music Studies, 1: 341-57.

47. Schippers, Huib (2016). 'Cities as Cultural Ecosystems: Researching and Understanding Music Sustainability in Urban Settings', Journal of Urban Culture Research, 12: 10-19.

48. Schippers, Huib and Catherine Grant, eds (2016). Sustainable Futures for Music Cultures:

An Ecological Perspective, New York: Oxford University Press.

49. Shank, Barry (2011). Dissonant Identities: The Rock'n’roll Scene in Austin, Texas, Middletown, CT: Wesleyan University Press.

50. Straw, Will (1991). 'Systems of Articulation, Logics of Change: Communities and Scenes in Popular Music’, Cultural Studies, 3: 368-88.

51. Straw, Will (2001). 'Scenes and Sensibilities’, Public, 22/23: 245-57.

52. Webster, Emma and Adam Behr (2013). 'Live Music 101\# 6-What Makes for a "Healthy” Musical City?’, Live Music Exchange, https://livemusicexchange.org/blog/live-music-101-6what-makes-for-a-healthy-musical-city-emma-webster-and-adam-behr/, 12 August 2019. 53. Wikström, Patrik (2009). The Music Industry: Music in the Cloud, Cambridge: Polity Press. 54. Williams, James Patrick (2007). 'Youth-Subcultural Studies: Sociological Traditions and Core Concepts’, Sociology Compass, 2: 572-93.

55. Williams, James Patrick (2011). Subcultural Theory: Traditions Cnd concepts, Cambridge: Polity Press.

56. Williams, James Patrick (2019). 'Subculture’s Not Dead! Checking the Pulse of Subculture Studies through a Review of "Subcultures, Popular Music and Political Change" and "Youth Cultures and Subcultures: Australian Perspectives”', Young, 1: 89-105. 